Bronchiolar lesions

intermittent positive pressure

ventilation (IPPV) newborn

respiratory distress syndrome ventilation, artificial breathing

\title{
Lung Surfactant and the Pathogenesis of Neonatal Bronchiolar Lesions Induced by Artificial Ventilation
}

\author{
ROLAND NILSSON,(2:) GERTIE GROSSMANN, AND BENGT ROBERTSON \\ Department of Pediatric Pathology, Karolinska Institutet, and Research Laboratory at the Department of \\ Pathology, St. Görans sjukhus, Stockholm, Sweden
}

\begin{abstract}
Summary
Premature newborn rabbits, obtained by hysterotomy on day 27 of gestation, were tracheotomized immediately after birth and treated with intermittent positive pressure ventilation (IPPV) for 16-60 min. Tidal volume was registered by means of a body plethysmograph and adjusted to $10 \mathrm{ml} / \mathrm{kg}$ and the insufflation pressure required to maintain this tidal volume was recorded. One group of animals received, by tracheal tube, a deposit of $50 \mu$ homologous surfactant suspension, prepared by centrifugation of lung wash from adult rabbits (the phospholipid content of the surfactant suspension was $8.4 \mathrm{mg} / \mathrm{ml}$, its lecithin content $6.9 \mathrm{mg} / \mathrm{ml}$ ); littermates with empty tracheal tubes served as controls. The mean quasistatic compliance of the lung-thorax system was higher in surfactant-treated animals than in controls $\left(0.42 \pm 0.12\right.$ and $0.27 \pm 0.04 \mathrm{ml} / \mathrm{cm} \mathrm{H} \mathrm{H}_{2} \mathrm{O} \cdot \mathrm{Kg}$, respectively; $P$ $<\mathbf{0 . 0 0 2})$. Alveolar expansion, determined morphometrically in histologic sections, was increased in animals receiving surfactant, in comparison with controls. Lung sections from control animals revealed widespread necrosis and desquamation of bronchiolar epithelium, whereas such lesions were scarce or absent in surfactant-treated animals. Our findings indicate that lung compliance of the premature neonate can be increased by deposition of surfactant in the upper airways before the onset of ventilation, and that deposition of surfactant prevents the development of bronchiolar epithelial lesions in premature neonates subjected to IPPV.
\end{abstract}

\section{Speculation}

The possibility that administration of supplementary surfactant might serve as a prophylaxis against RDS and against epithelial lesions induced by artificial ventilation should be further evaluated in animal experiments and the clinical application of analogous prophylactic measures considered, once synthetic surfactant suspensions with optimal phospholipid (or phospholipid-protein) composition have been defined.

The spectrum of structural abnormalities that characterize the lungs of infants dying from the neonatal RDS includes necrosis and desquamation of the bronchiolar epithelium $(5,6,21)$. This feature, which is particularly prominent in very immature infants who die from RDS within a few hours after birth, is part of the "natural" course of the disease, i.e., it is not restricted to patients receiving artificial ventilation. However, when a patient with severe RDS develops the complication known as "bronchopulmonary dysplasia," the degree of bronchiolar epithelial lesions appears to be correlated with the peak pressure used during artificial ventilation rather than with the dose of supplementary oxygen (20). This correlation suggests that intermittent positive pressure ventilation (IPPV) hampers the healing of the bron- chiolar epithelial lesions that develop in the early stage of the disease, or that the ventilation itself induces epithelial lesions identical to those in RDS. The latter concept is supported by the fact that necrosis of bronchiolar epithelium can be produced experimentally by subjecting immature newborn animals to brief periods of IPPV (13)

In earlier communications we have speculated that the bronchiolar lesions of RDS and those induced by artificial ventilation might have a common pathogenesis, i.e., overdistension of the terminal conducting airways secondary to a deficiency of surface active phospholipids in the fetal pulmonary fluid $(3,16,18)$. The aim of the present study was to test this theory experimentally on a series of premature newborn rabbits, treated with IPPV immediately after birth, with or without tracheal deposition of homologous surfactant before the onset of breathing. The results have been reported in preliminary form elsewhere $(14,15)$.

\section{PREPARATION OF SURFACTANT}

To obtain the homologous surfactant suspension, we washed the lungs of adult rabbits using a syringe attached to an endotracheal cannula. The lavage fluid was first centrifuged at $200 \times g$ and $20^{\circ}$ for $5 \mathrm{~min}$ to remove cellular contamination. then centrifuged at $1000 \times g$ and $4^{\circ}$ for $1 \mathrm{hr}$. This procedure yields a white pellet enriched in surface-active phospholipids (2). The pellets were resuspended in an equal volume of supernatant, then pooled and frozen until used for deposition. The phospholipid content of the surfactant pool used in the present experiments was $8.4 \mathrm{mg} / \mathrm{ml}$, the lecithin content $6.9 \mathrm{mg} /$ $\mathrm{ml}$.

\section{ARTIFICIAL VENTILATION OF FETUSES}

The experiments were carried out on 16 premature fetuses, obtained from 8 does. We killed the doe, 27 days less $1-3 \mathrm{hr}$ after mating (full term $=31 \pm 1$ day), by intravenous injection of $2 \mathrm{ml}$ Mebumal (sodium pentobarbital, $60 \mathrm{mg} / \mathrm{ml}$ ) and $5 \mathrm{ml}$ potassium chloride $(150 \mathrm{mg} / \mathrm{ml})$. The abdomen was immediately opened, and the blood vessels of the uterus were clamped with a large hemostat. The fetuses were delivered through random uterine incisions and weighed. We used two fetuses from each doe, one for deposition of surfactant and one serving as control. Body weight in surfactant-treated animals ranged between 26 and $34 \mathrm{~g}(\bar{\chi}=31, \mathrm{SD}=3)$, and in controls between 27 and 38 $\mathrm{g}(\bar{\chi}=31, \mathrm{SD}=3)$. Within a few seconds after delivery the fetuses received an intraperitoneal injection of $0.6 \mathrm{mg}$ Mebuman and $0.02 \mathrm{mg}$ Pavulon (pancuronium bromide). In order to prevent respiratory movements during this and the following procedure, the thorax of the fetus was gently compressed. The fetuses were tracheotomized, and in eight animals $50 \mu$ l surfactant suspension were deposited in the tracheal tube before the 


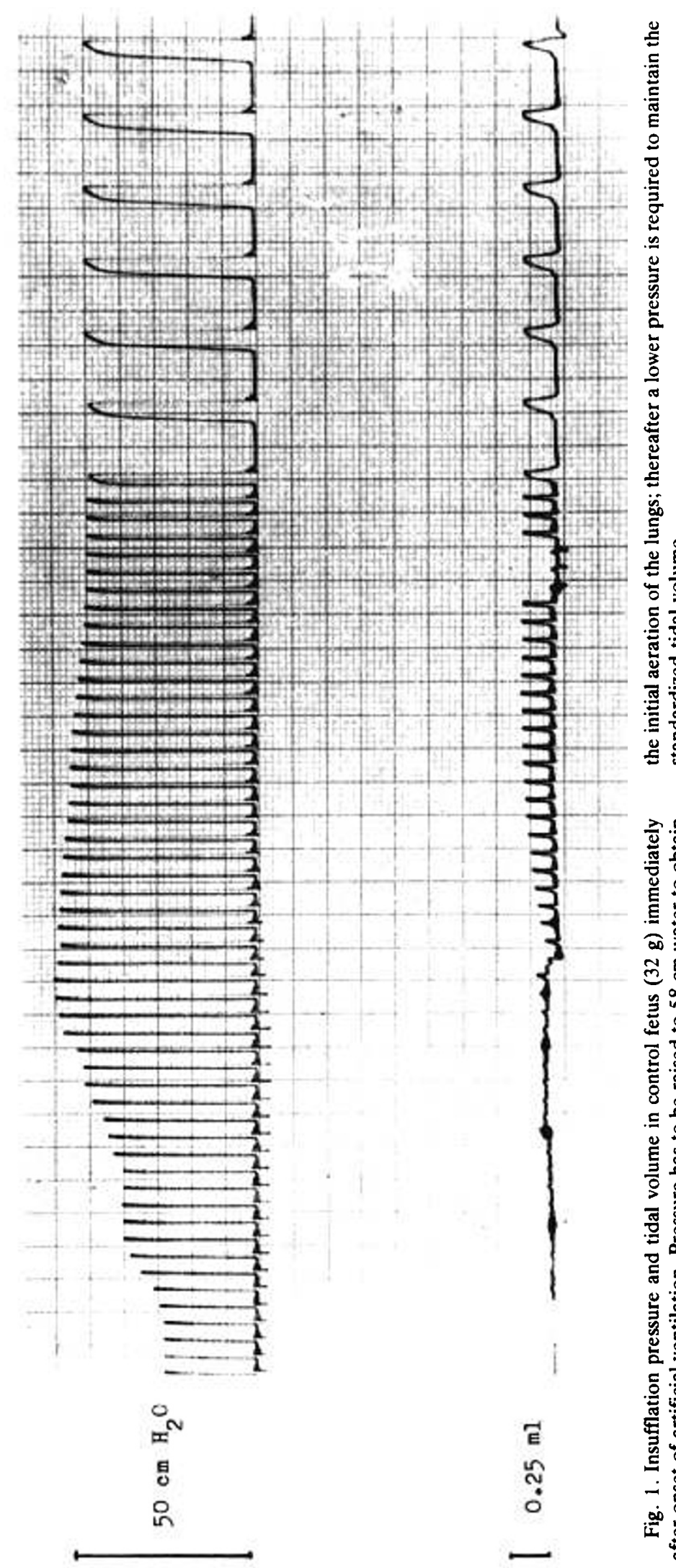

onset of ventilation; in control fetuses the tracheal cannula was empty.

Each fetus was kept at $37^{\circ}$ in a body plethysmograph with a constant volume of approximately $500 \mathrm{cc}$ and was connected to a Harvard 680 rodent ventilator. During the experiment the animals were fixed in dorsal position by needles through the paws; these needles also served as electrodes for ECG recording. The ventilator was set at a frequency of $60 / \mathrm{min}$ and the tidal volume, as registered by the body plethysmograph, adjusted to $10 \mathrm{ml} / \mathrm{kg}$ body weight ( a body plethysmograph was required for this purpose since we found that the pump volume read on the ventilator did not give accurate information on the amount of air entering the thorax of the animal). Pressure changes within the plethysmograph were registered by a pressure transducer (Siemens-Elema EMT $490 \mathrm{~B}$ ), after calibration by means of a 1$\mathrm{ml}$ syringe. Another pressure transducer (same type as above) was connected to the ventilator system immediately proximal to the tracheal cannula. We recorded the insufflation pressure required to maintain the standardized tidal volume, and since a pressure plateau was registered at end-inspiration we were able to calculate the quasistatic compliance of the lung-thorax system (12).

The duration of the experiment was $60 \mathrm{~min}$ in six pairs of fetuses. In one experiment the control fetus developed pneumothorax $34 \mathrm{~min}$ after the onset of artificial ventilation. In an other experiment we suspected (erroneously) from the configuration of the chest that pneumothorax had developed in the surfactant-treated fetus after $19 \mathrm{~min}$ of ventilation. In these experiments the artificial ventilation was discontinued in both surfactant-treated fetus and control as soon as the complication had occured.

\section{HISTOLOGIC AND MORPHOMETRIC TECHNIQUES}

Immediately after the period of artificial ventilation, we opened the chest of the fetus and perfused the lungs via the pulmonary artery with $2.5 \%$ buffered glutaraldehyde, at a pressure of $65 \mathrm{~cm}$ water. During the perfusion procedure $(15$ $\mathrm{min}$ ), the lungs were expanded at the endotracheal deflation pressure of $15 \mathrm{~cm}$ water. After the perfusion, the lungs and the heart were left in situ and kept in 10\% formalin for at least 24 hr. Lung volume after fixation was determined by water displacement according to the method of Scherle (17).

Paraffin sections from the basal portions of the lungs, stained with hematoxylin and eosin, were examined microscopically and the relative volumes of the alveolar spaces $\left(\mathrm{V}_{\mathrm{a}}\right.$, including alveolar duct spaces) and solid parenchyma ( $\mathrm{V}_{\mathrm{p}}$, including interalveolar septa, vessels, bronchial, and bronchiolar walls) were determined by the point-counting technique (1). The alveolar expansion index $\left(I_{a}\right)$ was calculated by the formula: $I_{a}$ $=\mathrm{V}_{\mathrm{a}} / \mathrm{V}_{\mathrm{p}}(2)$.

We also examined the same sections with particular reference to bronchiolar epithelial lesions and hyaline membranes. In each fetus the total number of high power fields (HPF) showing any of these lesions was counted and related to the total number of HPFs examined; an index of the extent of bronchiolar epithelial lesions was obtained from the ratio between these two figures, multiplied by the alveolar expansion index to correct for variations in the volume of the alveolar compartment that might influence the spacing of the bronchioles:

$$
\frac{\text { No. of HPFs with lesion }}{\text { No. of HPFs examined }} \times I_{a}
$$

The Wilcoxon two-sample test and regression analysis were used for statistical evaluation.

\section{RESULTS}

In the initial phase of the experiment a comparatively high insufflation pressure was required to obtain the standardized 


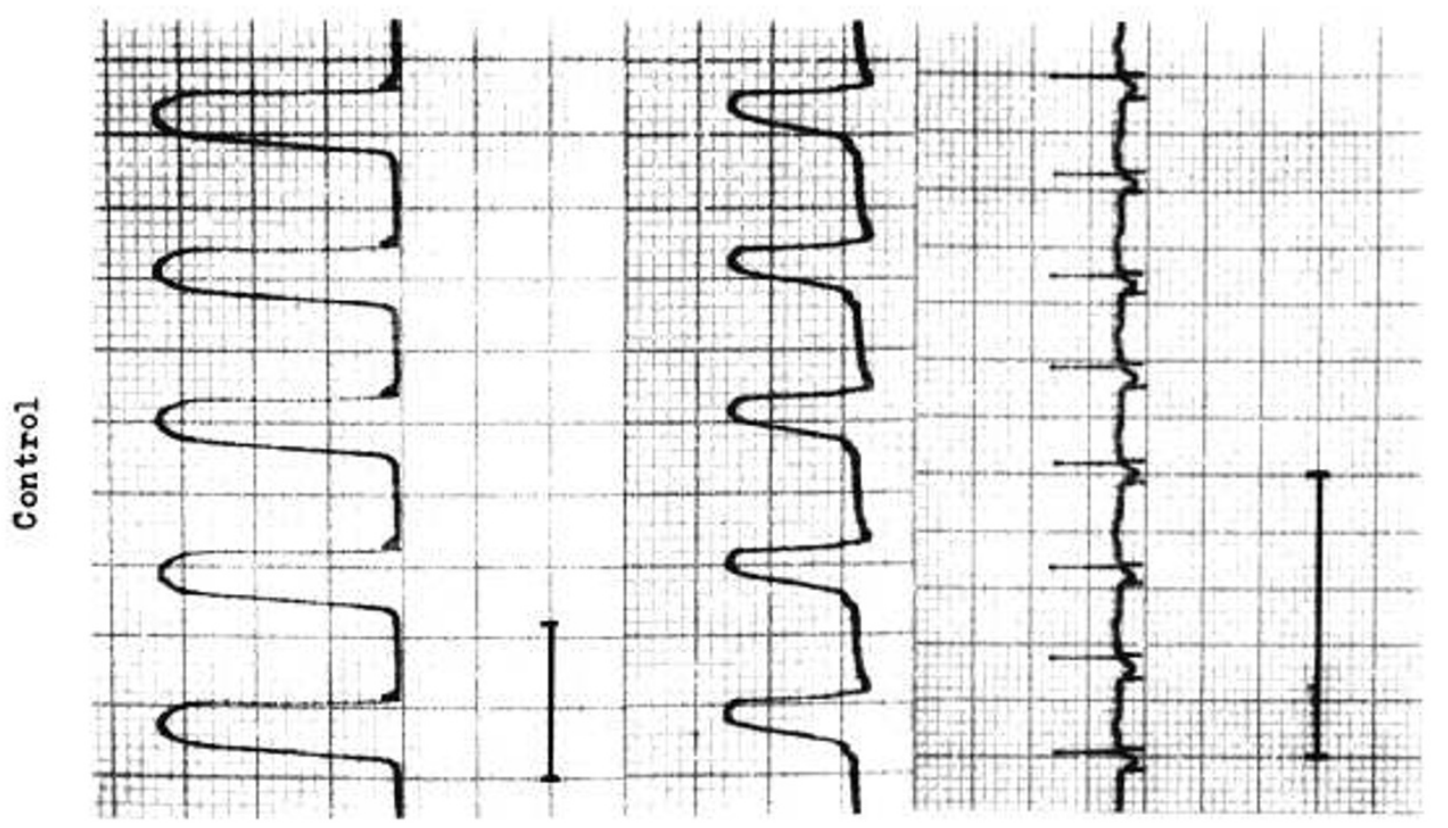

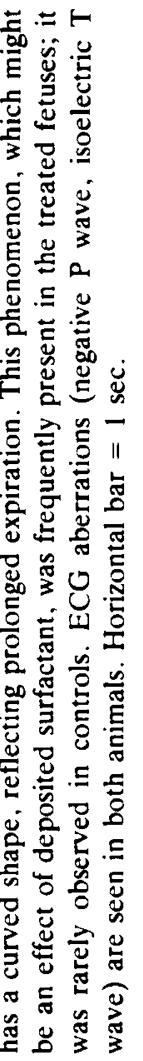

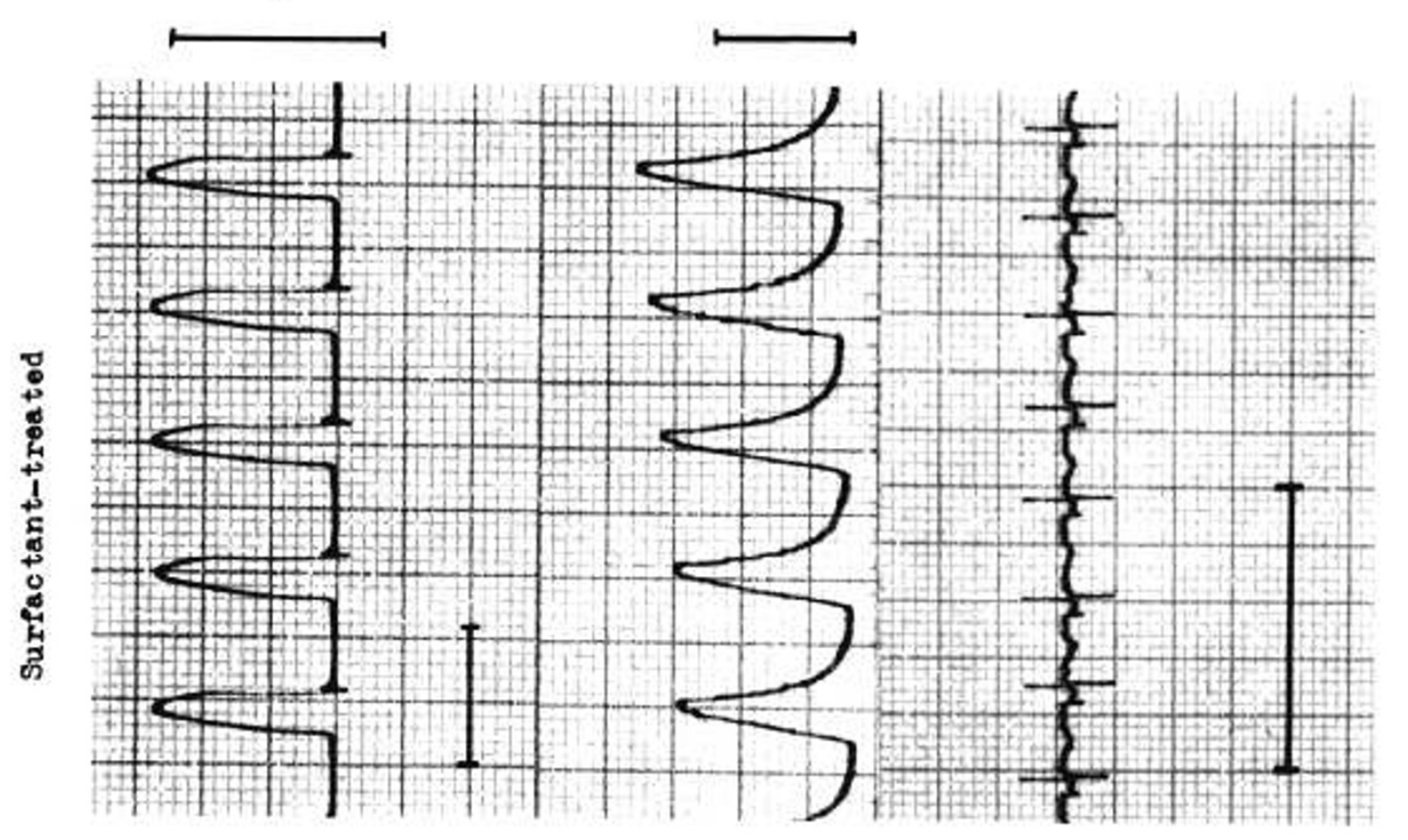

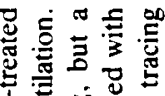

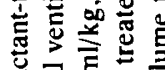

蛋

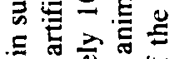

员跣

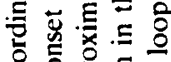

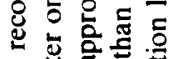

记产行

है है ह

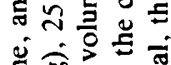

实

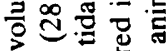

즐 흘

를

氙 范

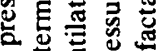

ᄃ

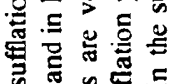

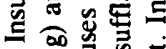

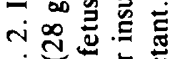

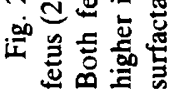


tidal volume; thereafter the same tidal volume could be maintained with a lower insufflation pressure (Fig. 1). However, both in the initial phase of lung aeration and during the subsequent course of the experiment, the surfactant-treated animals could be ventilated with a lower end-inspiratory pres-

Table 1. Maximal insufflation pressure during initial air expansion of lungs ("opening pressure") and insufflation pressure during IPPV with standardized tidal volume $(10 \mathrm{ml} / \mathrm{kg}$ body weight) ${ }^{1}$

\begin{tabular}{|c|c|c|c|c|}
\hline \multirow[b]{2}{*}{$\begin{array}{l}\text { Time interval } \\
(\mathrm{min})\end{array}$} & \multirow[b]{2}{*}{$n$} & \multicolumn{2}{|c|}{$\begin{array}{c}\text { Insufflation pressure (cm } \\
\left.\mathrm{H}_{2} \mathrm{O}, \text { mean } \pm \mathrm{SD}\right)\end{array}$} & \multirow[b]{2}{*}{$P$} \\
\hline & & $\begin{array}{l}\text { Surfactant- } \\
\text { treated } \\
\text { animals }\end{array}$ & Controls & \\
\hline Opening pressure & $7+7$ & $37 \pm 8$ & $47 \pm 11$ & $<0.05$ \\
\hline $0-10$ & $8+8$ & $27 \pm 5$ & $38 \pm 6$ & $<0.01$ \\
\hline $11-20$ & $7+7$ & $25 \pm 4$ & $35 \pm 4$ & $<0.002$ \\
\hline $21-30$ & $7+7$ & $23 \pm 3$ & $35 \pm 3$ & $<0.002$ \\
\hline $31-40$ & $6+6$ & $22 \pm 7$ & $34 \pm 2$ & NS \\
\hline $41-50$ & $6+6$ & $22 \pm 7$ & $34 \pm 1$ & NS \\
\hline $51-60$ & $6+6$ & $22 \pm 7$ & $33 \pm 2$ & NS \\
\hline
\end{tabular}

1 Values are given for surfactant-treated animals and contrels at various intervals after onset of ventilation. sure than controls (Fig. 2, Table 1). This difference in compliance of the lung-thorax system was statistically significant at all intervals after the onset of ventilation, except for the last 10-min period of observation (Table 2 ). In surfactant-treated animals compliance increased with time $(r=0.46 ; P<0.01)$.

At all intervals, mean heart rate was lower in controls (range $169 \pm 40$ to $208 \pm 33$ ) than in surfactant-treated animals (range $195 \pm 26$ to $238 \pm 21$ ), but the difference was statistically significant only for the time period $11-20 \mathrm{~min}(P<0.02)$.

Table 2. Compliance of lung-thorax system in surfactant-treated animals and controls at various time intervals after onset of artificial ventilation

\begin{tabular}{|c|c|c|c|c|}
\hline \multirow[b]{2}{*}{$\begin{array}{c}\text { Time } \\
\text { interval } \\
(\mathrm{min})\end{array}$} & \multirow[b]{2}{*}{$n$} & \multicolumn{2}{|c|}{$\begin{array}{c}\text { Compliance }\left(\mathrm{ml} / \mathrm{cm} \mathrm{H}_{2} \mathrm{O} \cdot \mathrm{kg} \text { body }\right. \\
\text { wt) mean } \pm \mathrm{SD}\end{array}$} & \multirow[b]{2}{*}{$P$} \\
\hline & & $\begin{array}{c}\text { Surfactant- } \\
\text { treated } \\
\text { animals }\end{array}$ & Controls & \\
\hline $0-10$ & $8+8$ & $0.30 \pm 0.07$ & $0.23 \pm 0.06$ & $<0.01$ \\
\hline $11-20$ & $7+7$ & $0.40 \pm 0.07$ & $0.27 \pm 0.04$ & $<0.01$ \\
\hline $21-30$ & $7+7$ & $0.43 \pm 0.08$ & $0.27 \pm 0.02$ & $<0.002$ \\
\hline $31-40$ & $6+6$ & $0.48 \pm 0.13$ & $0.29 \pm 0.01$ & $<0.05$ \\
\hline $41-50$ & $6+6$ & $0.48 \pm 0.11$ & $0.28 \pm 0.02$ & $<0.02$ \\
\hline $51-60$ & $6+6$ & $0.47 \pm 0.12$ & $0.29 \pm 0.02$ & NS \\
\hline
\end{tabular}

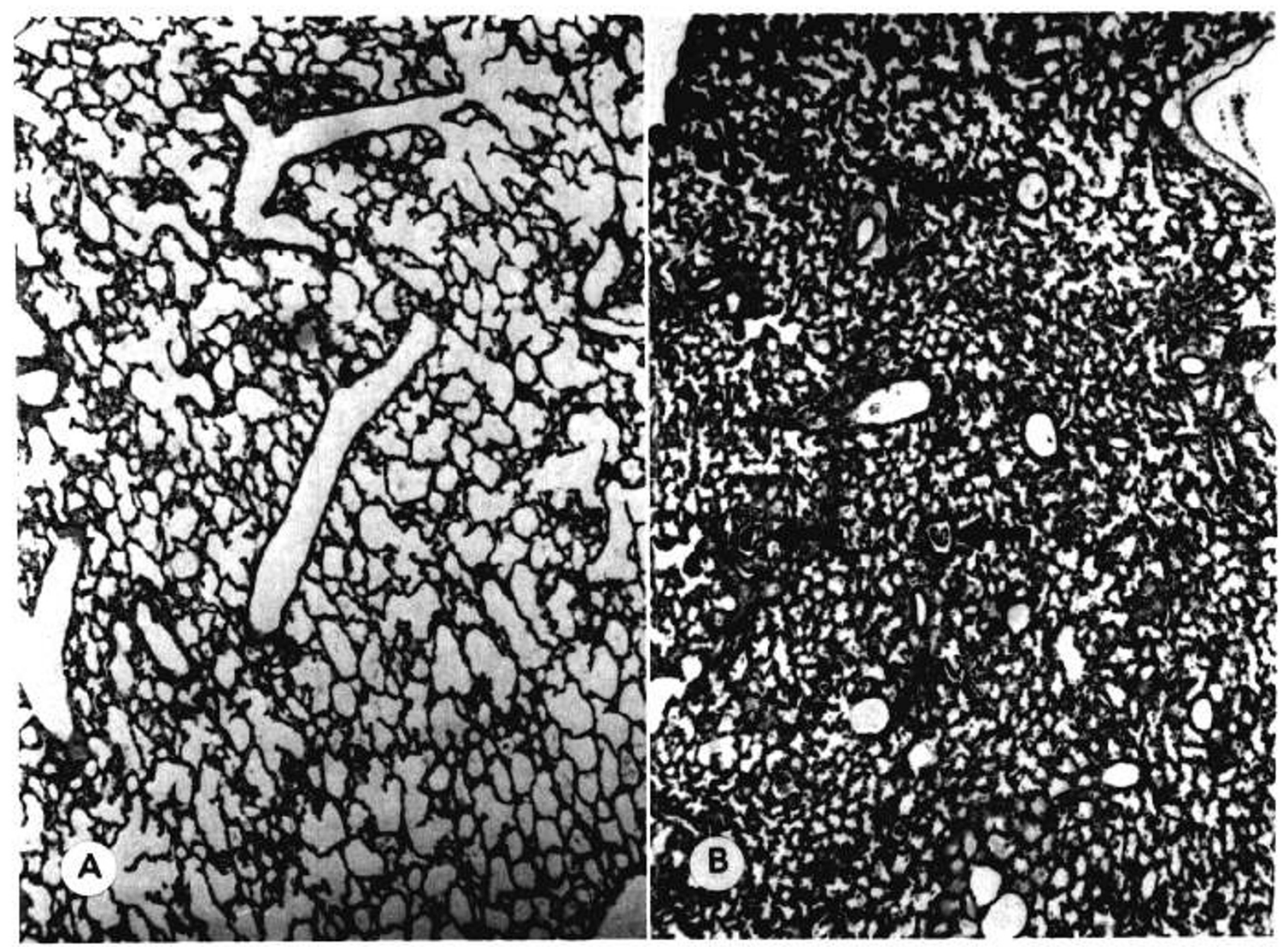

Fig. 3. Low power fields showing histologic sections of lungs from surfactant-treated fetus $(A)$ and littermate control $(B)$. In the surfactanttreated animal the lung parenchyma is fairly well aerated and the epithelium of the conducting airways is intact. In the control animal the parenchyma is largely nonaerated, and there is widespread necrosis and desquamation of bronchiolar epithelium (arrows). Hematoxylin and eosin, $\times 50$. 
Minor ECG aberrations (such as diphasic P wave, and low, isoelectric, or inverted $\mathrm{T}$ wave) were frequent in both groups of animals and in the control fetus that developed pneumothorax we registered a complete atrioventricular block 25-34 min after the onset of ventilation.

Lung volume after fixation was the same in surfactant-treated animals and controls, but there was a statistically significant difference between the two groups as to the relative volume of the alveolar compartment; the mean alveolar expansion index was $67 \%$ higher in the treated animals $(P<0.05$, Table 3$)$.

A difference in alveolar expansion pattern was obvious also on conventional histologic examination. In surfactant-treated animals the lung parenchyma was better aerated than in controls, although the expansion pattern was usually irregular, with unexpanded areas alternating with areas of well aerated or

Table 3. Lung volume and alveolar expansion index in surfactant-treated animals and controls

\begin{tabular}{lccc}
\hline & \multicolumn{3}{c}{ Mean \pm SD } \\
\cline { 2 - 3 } & $\begin{array}{c}\text { Surfactant-treated } \\
\text { animals } \\
(n=8)\end{array}$ & $\begin{array}{c}\text { Controls } \\
(n=8)\end{array}$ & $P$ \\
\hline $\begin{array}{l}\text { Lung volume (ml) } \\
\text { Alveolar expansion in- } \\
\text { dex }\end{array}$ & $1.17 \pm 0.15$ & $1.18 \pm 0.19$ & NS \\
\hline
\end{tabular}

overexpanded alveoli (Fig. 3A). The lungs of control fetuses, on the other hand, had largely retained their fetal appearance, characterized by fluid-filled alveoli with wrinkled walls; in these lungs there were only minor areas of air-expanded alveoli (Fig. $3 B$ ). In one control animal, there was prominent intraalveolar hemorrhage.

In animals receiving surfactant, bronchiolar epithelial lesions were characteristically absent or scarce (Fig. $4 A$ ). One of the surfactant-treated animals, however, and all controls had widespread necrosis and desquamation of bronchiolar epithelium, with nuclear debris and hyaline membranes in preterminal

Table 4. Index of bronchiolar epithelial lesions in surfactanttreated animals and controls in relation to duration of artificial ventilation

\begin{tabular}{|c|c|c|c|c|}
\hline \multirow[b]{2}{*}{$\begin{array}{l}\text { Artificial } \\
\text { ventilation } \\
(\min )\end{array}$} & \multirow[b]{2}{*}{$n$} & \multicolumn{2}{|c|}{$\begin{array}{c}\text { Index of bronchiolar epithelial le- } \\
\text { sions } \\
(\text { Mean } \pm \text { SD) }\end{array}$} & \multirow[b]{2}{*}{$P$} \\
\hline & & $\begin{array}{l}\text { Surfactant- } \\
\text { treated } \\
\text { animals }\end{array}$ & Controls & \\
\hline $16-19$ & $1+1$ & 0 & 0.22 & \\
\hline $34-41$ & $1+1$ & 0.08 & 0.46 & \\
\hline 60 & $6+6$ & $0.04 \pm 0.09$ & $0.34 \pm 0.05$ & $<0.01$ \\
\hline Total & $8+8$ & $0.04 \pm 0.08$ & $0.34 \pm 0.07$ & $<0.002$ \\
\hline
\end{tabular}

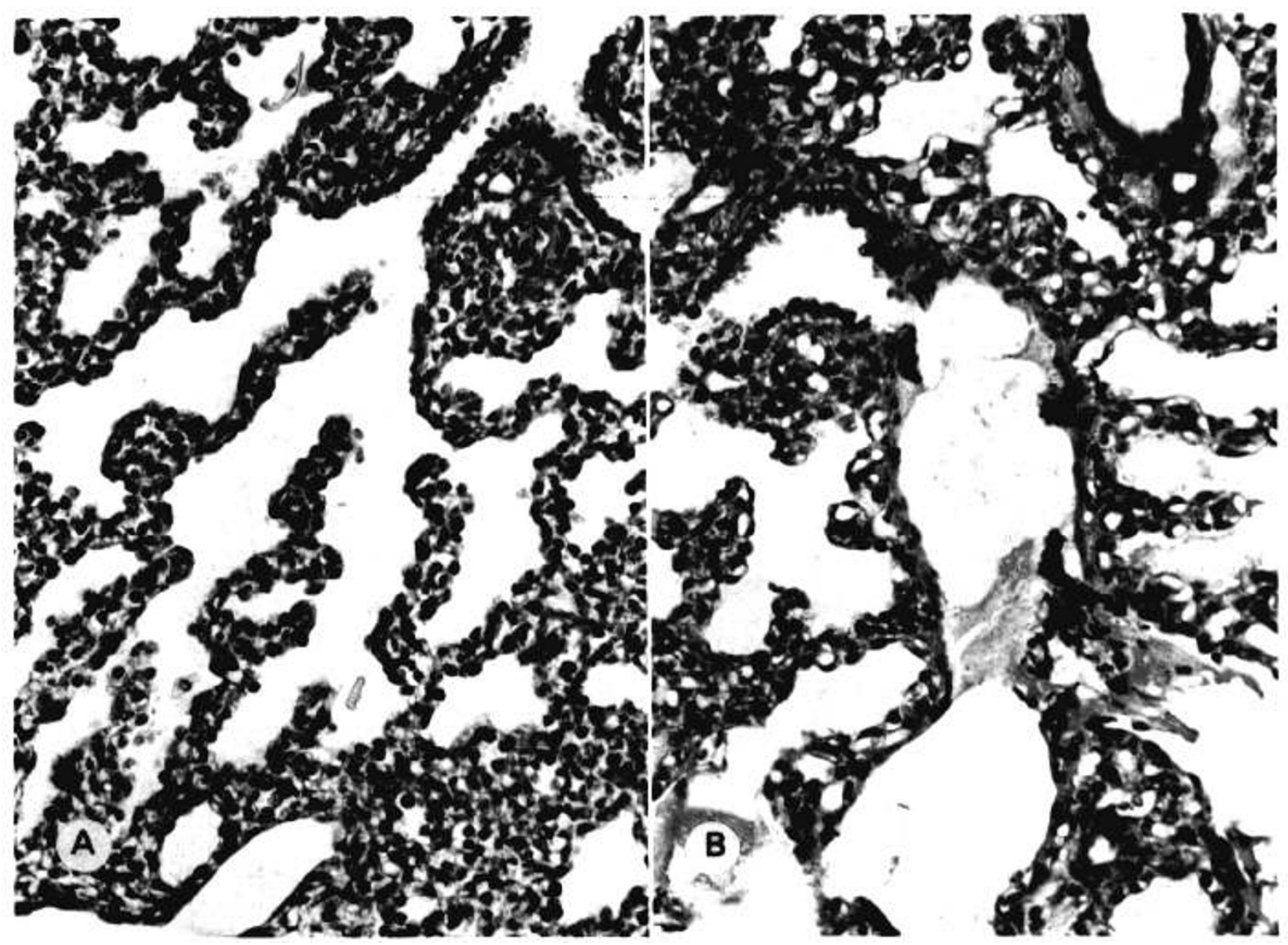

Fig. 4. Details of histologic lung sections from surfactant-treated animal $(A)$ and littermate control $(B)$, both ventilated for 60 min. In the surfactant-treated animal, the bronchiolar epithelium is intact $(A$, right upper $)$; in the control animal the bronchiolar epithelium is necrotic and desquamated, and the preterminal airspaces contain cellular debris embedded in hyaline membranes. Hematoxylin and eosin, $\times 300$. 
airspaces (Fig. $4 B$ ). The difference between the two groups was clearly borne out by the morphometric analysis; the mean index of bronchiolar epithelial lesions was only 0.04 in surfactanttreated animals, but 0.34 in controls $(P<0.002$. Table 4$)$.

\section{DISCUSSION}

The results of the present study confirm carlier observations $(13,18)$ by showing that bronchiolar epithelial lesions, equivalent to those in RDS, can be induced in newborn experimental animals by IPPV. However, in contrast to carlier studies in this field, the present report gives information on tidal volume and insufflation pressure during the experimental procedure. We chose a tidal volume which should ensure adequate aeration of the pulmonary parenchyma, provided that the lungs expanded in a uniform and physiologic manner, and found that in control animals the maintenance of this tidal volume required insufflation pressures ranging up to $48 \mathrm{~cm}$ water. In this respect, the lungs of our controls were similar to those of newborn infants with severe RDS; in these patients analogous high insufflation pressures often have to be applied during the period of assisted ventilation.

The epithelial lesions produced under the present experimental conditions and the epithelial lesions of RDS have many features in common, viz., localization to the terminal conducting airways, desquamation of epithelium, and formation of hyaline membranes containing nuclear debris. As mentioned in the introductory section, these morphologic changes might reflect overdistention of bronchioles with subsequent mechanical disruption of the epithelium $(3,16,18)$. In our opinion, this mechanism could be an important factor also in the pathogenesis of the "natural" epithelial lesions in RDS, as well as in the aggravation of these lesions in RDS patients treated with IPPV.

The latter concept is supported by the fact that patients who survive neonatal RDS and who have been treated with IPPV tend to develop increased airway resistance. This complication, which occurs as an isolated phenomenon, in the absence of radiologic evidence of "bronchopulmonary dysplasia." indicates that IPPV applied in the neonatal period induces chronic bronchial and bronchiolar lesions and that it hampers the growth of conducting airways during the first year of life (19).

The part of the aforementioned theory $(3,16,18)$ that incriminates deficiency of lung surfactant as the underlying cause of bronchiolar overexpansion, gains support by the present observation that the liability to develop epithelial lesions is dramatically reduced by deposition of homologous surfactant before the onset of ventilation. The dose of homologous surfactant used in the present experiments compensates for the deficiency of intraalveolar phospholipids at this stage of gestation $(2,7,11)$, and when applied in the upper airways of premature animals before the first breath, it greatly enhances neonatal lung aeration. This also occurs during spontaneous ventilation $(2,4)$.

Direct microscopic inspection of the lung surface during pressure/volume recording, as well as studies of lung expansion in histologic sections, have revealed that alveolar aeration is more uniform in premature experimental animals receiving supplementary surfactant than in controls $(2,3,9)$. Thus, if the lungs of premature animals are ventilated with a standardized tidal volume, the risk of bronchiolar overdistension with subsequent epithelial lesions should be greater in controls than in animals receiving supplementary surfactant. This is one possible explanation of the fact that epithelial lesions were abundant in all control fetuses but absent in most surfactant-treated ones.

An alternative explanation is that in the control group the higher airway pressure per se could account for the epithelial lesions. This aspect of the problem could not be analyzed in depth with the present experimental model. We preferred to ventilate the animals with a standardized tidal volume rather than with a standardized insufflation pressure, since preliminary experiments had revealed that unless a comparatively high insufflation pressure was applied, the control animals died shortly after birth and if an equivalent high pressure was used in the surfactant-treated animals they developed pneumothorax.

Improved pressure/volume characteristics have been found in earlier studies on lung preparations from premature rabbit neonates receiving thacheal deposition of surfaciant (3), but the present work is the first to document in vivo the beneficial effect of surfactant deposition on lung compliance. Although our method for measuring compliance does not differentiate between lung and chest wall compliance, we assume that the difference between surfactant-treated animals and controls is due chiefly to a modification of the surface properties of the fetal pulmonary fluid in the former group. The fact that compliance increased with time in the surfactant-treated animals can be related both to a gradual maturation (adsorption) of the surface film in the terminal airspaces and to a resorption of fetal pulmonary fluid. Earlier electron microscopic studies have shown that the formation of a "mature" alveolar lining layer is a matter of hours even in the fullterm rabbit neonate (10).

Our finding that lung volume after fixation was identical in surfactant-treated animals and controls, whereas the alveolar expansion index was higher in the former group, indicates that the volume of solid parenchyma was reduced in animals receiving surfactant. This interpretation is in keeping with our earlier observation that the lung weight of premature rabbit neonates receiving supplementary surfactant is, indeed, reduced after birth, although not to the same extent as in fullterm newborn animals (8).

\section{REFERENCES AND NOTES}

1. Chalkley, H. W.: Method for the quantitative morphologic analysis of tissues. J. Nat. Cancer Inst., 4: 47 (1943).

2. Enhörning, G., Grossmann, G., and Robertson, B.: Tracheal deposition of surfactant before the first breath. Amer. Rev. Resp. Dis.. 107: 921 (1973).

3. Enhörning, G.. and Robertson, B.: Lung expansion in the premature rabbit fetus after tracheal deposition of surfactant. Pediatrics, 50: 58 (1972).

4. Enhörning. G.. Robertson, B., Milne, E., and Wagner, R.: Radiologic evaluation of the premature newborn rabbit after pharyngeal deposition of surfactant. Amer. J. Obstet. Gynecol., 121: 475 (1975).

5. Finlay-Jones, J. M., Papadimitriou, J. M., and Barter, R. A.: Pulmonary hyaline membrane: Light and electron microscopic study of the early stage. J. Pathol., I12: 117 (1974).

6. Gandy, G., Jacobsson. W., and Gairdner, D.: Hyaline membrane disease. I. Cellular changes. Arch. Dis. Childhood, 45: 289 (1970).

7. Gluck, L., Motoyama, E. K., Smits, H. L., and Kulovich, M. V.: The biochemical development of surface activity in mammalian lung. 1 . The surface-active phospholipids; the separation and distribution of surfaceactive lecithin in the lung of the developing rabbit fetus. Pediat. Res.. l: 237 (1967).

8. Grossmann, G.: Lung-weight: body-weight ratio in the premature newborn rabbit after tracheal deposition of surfactant. IRCS Med. Sci., 4: 235 (1976).

9. Grossmann. G.: Expansion pattern of terminal air-spaces in the premature rabbit lung after tracheal deposition of surfactant. Pflügers Arch. Ges. Physiol., 367: 205 (1977).

10. Grossmann, G., and Robertson, B.: Lung expansion and the formation of the alveolar lining layer in the fullterm new born rabbit. Acta Paediat. Scand., Vol. 64: 9, 1975.

11. Kikkawa, Y., Motoyama, E. K.. and Gluck, L.: Study of the lungs of fetal and newborn rabbits: Morphologic, biochemical, and surface physical development. Amer. J. Pathol., 52: 177 (1968).

12. Lachmann, B., Bergmann. K. C., Winsel, K., Müller, E., Petro, W., Schafer, C.. and Vogel, J.: Experimentelles Atemnotsyndrom nach Injection von Anti-Lungen-Serum. III. Mitteilung: Atemmechanische, Blutgas-analytische, physikochemische und biochemische Befunde im chronischen Versuch; Therapieversuche. Pädiatrie Grenzgeb., 4: 211 (1975).

13. McAdams, A. J., Coen, R., Kleinman, L. 1., Tsang, R., and Sutherland, J.: The experimental production of hyaline membranes in premature rhesus monkeys. Amer. J. Pathol., 70: 277 (1973).

14. Nilsson. R.. Grossmann. G.. and Robertson, B.: Lung surfactant and the expansion pattern of terminal airspaces during neonatal adaptation. Symposium on Lung Lipid Metabolism. Mechanisms of its Regulation and Alveolar Surfactant, Varna, Bulgaria, 1976 (In press).

15. Nilsson, R., Grossmann, G., and Robertson, B.: Pathogenesis of neonatal bronchiolar epithelial lesions induced by artificial ventilation. Med. Sci.. 5: 272, (1977).

16. Robertson. B.: Current and counter-current theories on lung surfactant. Scand. J. Resp. Dis., 57: 199 (1976).

17. Scherle. W.: A simple method for volumetry of organs in quantitative stereology. Microscopy, 26: 57 (1970).

18. Schwieler, G. H., and Robertson, B.: Liquid ventilation in immature newborn 
rabbits. Biol. Neonate, 29: 343 (1976).

19. Stocks, J., and Godfrey, S.: The role of artificial ventilation, oxygen and CPAP in the pathogenesis of lung damage in neonates. Pediatrics, 57: 352 (1976).

20. Taghizadeh, A., and Reynolds, E. O.: Pathogenesis of bronchopulmonary dysplasia following hyaline membrane disease. Amer. J. Pathol., 82: 241 (1976).

21. Tregillus, J.: The asphyxial membrane in the lungs of liveborn infants. J.

Copyright (c) 1978 International Pediatric Research Foundation, Inc. $0031-3998 / 78 / 1204-0249 \$ 02.00 / 0$
Obstet. Gynecol. Brit. Emp., 58: 406 (1951).

22. This research was supported by the Swedish Medical Research Council (Project No 12X-3351) and by "Karolinska Institutets anslag för ograduerade forskare."

23. Requests for reprints should be addressed to: Barnpatologiska Forskningslaboratoriet, St. Görans sjukhus, S-112 81 Stockholm (Sweden).

24. Received for publication May 5, 1977.

25. Accepted for publication July 27,1977 